\title{
A PRODUÇÃO DO CONHECIMENTO EM POLÍTICẢS E GESTÃO DA EDUCAÇÃO
}

\author{
THE PRODUCTION OF KNOWLEDGE IN \\ EDUCATIONAL POLICY AND MANAGEMENT \\ LA PRODUCTION DU SAVOIR DANS LES \\ POLITIQUES ET GESTION ÉDUCATIONNELLES \\ LA PRODUCCIÓN DEL CONOCIMIENTO EN \\ POLÍTICAS Y GESTIÓN DE LA EDUCACIÓN
}

\author{
Benno Sander*
}

\section{RESUMO}

O estudo da produção do conhecimento em políticas e gestão da educação tem merecido atenção prioritária nos meios acadêmicos e profissionais do Brasil. Este trabalho insere-se nesse esforço intelectual. Seu objetivo é examinar duas vertentes que hoje ocupam crescente espaço na literatura especializada: a gestão produtiva, voltada para o mercado, e a gestão democrática, comprometida com a cidadania. A primeira vertente insere-se no contexto da lógica econômica e comercial própria da atual sociedade globalizada. A segunda é uma conquista dos movimentos sociais que lutam pela promoção da qualidade de vida humana na escola e na sociedade, definida em termos de participação eqüitativa nos bens econômicos e culturais produzidos coletivamente.

Palavras-chave: Políticas públicas. Política educacional. Gestão democrática versus gestão produtiva em educação. Participação. Cidadania.

* Doutor em Educação pela Catholic University of America em Washington, DC (EUA, 1970). Consultor Internacional em Educação. Professor Titular aposentado da Universidade Federal Fluminense UFF-RJ (bennosander@terra.com.br). 


\section{INTRODUÇÃO}

O estudo da produção do conhecimento em matéria de políticas e gestão da educação tem merecido atenção prioritária nos meios acadêmicos e tem sido tema recorrente nos debates promovidos nas últimas décadas nos foros educacionais do País. Essa atenção é evidente, por exemplo, nos recentes trabalhos da Associação Nacional de Pós-Graduação e Pesquisa em Educação (Anped) e da Associação Nacional de Política e Administração da Educação (Anpae). O presente trabalho, que visa examinar algumas vertentes da experiência brasileira de construção do conhecimento no campo da política e da gestão da educação, reflete esse esforço intelectual.

O tema das políticas educacionais insere-se no contexto mais amplo das políticas públicas, que tem sido foco central do Grupo de Trabalho sobre Estado e Politicas Públicas da Anped, cuja agenda reflete a efervescência intelectual das últimas décadas, inserindo-se no debate epistemológico sobre o pensar e o fazer a educação no Brasil e, nesse contexto, sobre a formulação e execução de políticas públicas em educação.

A mesma efervescência intelectual caracterizou o trabalho da Associação Nacional de Política e Administração da Educação (Anpae) das últimas décadas. Em 1981, a Faculdade de Educação da Universidade de São Paulo foi sede de encontro nacional, promovido pela Anpae, que reuniu pensadores e administradores educacionais do País para examinar a experiência brasileira em matéria de política e gestão da educação, tratando de desconstruir e reconstruir o pensamento político e administrativo no campo do ensino, em termos de quatro perspectivas analíticas, correspondendo a quatro movimentos que influenciaram os destinos da educação no século XX: (1) a administração para a eficiência econômica, que floresceu no início de século e se consolidou a partir da I Gruerra Mundial; (2) a administração para a eficácia técnica, que se impôs como instrumento de recuperação da recessão que se abateu sobre o mundo no final da década de 1920; (3) a administração para a efetividade política, que caracterizou o esforço desenvolvimentista após a II Guerra Mundial; e (4) a administração para a relevância cultural, impulsionada pelos movimentos sociais da segunda metade do século XX, culminando na consolidação dos valores democráticos, que têm expressão na queda do Muro de Berlim e, no Brasil, na abertura política das últimas décadas (SANDER, 1982). Inúmeras obras educacionais, de natureza interacionista e ancoradas em renovados valores e compromissos éticos, surgiram nessa época para fazer frente às tradicionais perspectivas funcionalistas e reprodutivistas da pedagogia positivista que caracterizou a história republicana.

Vinte anos mais tarde, acentua-se o debate sobre a construção do conhecimento em políticas e gestão da educação no País. Nova reunião se realiza em 2001, na Faculdade de Educação da Universidade de São Paulo, que examina quatro momentos de nossa caminhada histórica em matéria de políticas públicas e gestão da educação no Brasil: $o$ momento da colonização, caracterizado pelo normativismo político e legalismo administrativo, que se estende do século XVI ao século XVIII; o momento da ordem e do progresso, influenciado pelo positivismo filosófico que marcou a Primeira República; o momento da economia da educação do período desenvolvimentista da pós-guerra; e o momento da reconstrução democrática das últimas décadas (SANDER, 2001). 
É nesse contexto histórico que este trabalho volta a examinar alguns esforços de construção do conhecimento em matéria de política e gestão da educação. Ao invés de tentar cobrir a vasta literatura brasileira sobre matéria tão extensa, o trabalho se limita a examinar duas grandes vertentes que hoje caracterizam a gestão da educação brasileira, uma definida pelas forças do mercado e outra comprometida com a promoção da cidadania. $\mathrm{O}$ objetivo desse exercício é abrir portas em direção a distintas possibilidades de reflexão sobre o estado da arte em matéria de políticas públicas e gestão da educação no Brasil.

\section{CONCEPÇÕES POLITICAS E ADMINISTRATIVAS NO GOVERNO DA EDUCAÇÃO}

O estudo das concepções políticas e administrativas que influenciam os destinos da educação brasileira requer, antes de mais nada, uma definição de termos, acompanhada de uma discussão de suas implicações políticas e pedagógicas. Administração, gestão, governo, governação, governança e governabilidade são hoje termos amplamente utilizados no vocabulário educacional e estão presentes, há muito tempo, nos nossos dicionários da língua portuguesa.

As políticas que informam a ação humana e a condução dos destinos dos povos, tribos e seitas religiosas, agremiaçōes partidárias, corporaçōes militares e instituições humanas em geral são práticas milenares. Nessas práticas, a história da humanidade registra o papel central do líder e do profeta, do pastor ou cacique, do chefe ou diretor, do faraó, monarca ou presidente, enfim, do governante atuando em distintas instâncias e realidades sociais.

A preocupação com a sistematização das práticas de organização e administração, tal como as conhecemos no mundo ocidental, se manifesta a partir do século XIX, por ocasião da explosão organizacional imposta pela Revolução Industrial. Com a consolidação da Revolução Industrial, no início do século XX, surgiram as teorias de administração, protagonizadas por Taylor (1911), nos Estados Unidos da América, Fayol (1916), na França, e Weber (1921), na Alemanha.

Essas teorias, que integram a denominada escola clássica de administração, estabeleceram princípios e estruturas organizacionais para guiar a ação de governo na indústria e no comércio, no Estado e na Igreja, na escola e nas instituições humanas em geral. Cada um dos protagonistas das teorias clássicas tinha por objetivo desenvolver uma teoria geral de administração, com políticas e práticas aplicáveis à condução dos destinos de qualquer organização humana, independentemente de sua natureza e de seus objetivos. Em muitos aspectos, no entanto, as teorias gerais de administração não resistiram ao tempo. No transcurso dos anos, a natureza do objeto governado foi definindo, com maior ou menor alcance, a própria natureza da ação administrativa. Consolidaram-se, assim, a administração empresarial, iniciada com o enfoque científico da teoria gerencial de Taylor, a administração industrial, concebida por Fayol, e a administração pública, protagonizada por Willoughby (1929) no contexto da ciência política. Esses desenvolvimentos deram origem ao princípio da especificidade no campo da administração. Foi à luz desse princípio que se desenvolveu, ao longo dos anos, a administração da educação, como campo de estudo e atividade profissional. 
Foi no mundo da administração industrial e comercial que a produção do conhecimento tomou a dianteira, inicialmente movida pela ética protestante, amplamente interpretada na obra sociológica de Weber (1921). Seguiu-lhe a administração pública, aliada à ciência política e influenciada pela teoria weberiana da burocracia e, posteriormente, pelo enfoque comercial da administração de negócios. No âmbito da administração empresarial, à luz da própria concepção taylorista de management, desenvolveram-se novos conceitos administrativos, como os de gestão e gerência, que rapidamente invadiram as distintas áreas temáticas da administração. Surgiram, assim, os cargos de gestor e gerente, em substituição ou adição aos de administrador e diretor.

No campo da educação, a orientação e a direção das práticas de formação humana também constituem prática milenar, com inúmeros registros na história do Oriente e do Ocidente. Na civilização ocidental, a orientação política da educação e as práticas de formação humana têm raízes na paidea grega e nos ensinamentos do Cristianismo, passando pelos pensadores do Império Romano. A partir da Idade Média, com a consolidação dos sistemas de ensino na Europa, impôs-se a necessidade de organizar mais sistematicamente as atividades do ensino, que, naquela época, eram majoritariamente delegadas a sacerdotes e religiosos. Essa circunstância deu origem a modalidades de gestão educativa de natureza normativa e prescritiva, na linha da tradição monárquica européia e da filosofia escolástica, com um enquadramento jurídico ditado pelo direito administrativo romano.

$\mathrm{Na}$ realidade, através dos tempos, o ensino e sua organização sempre tiveram um caráter essencialmente normativo e prescritivo. Esse caráter se manifesta na própria didática tradicional, que parte do princípio de que o aluno deve aprender aquilo que o professor ensina e não aquilo que deseja aprender. Tradicionalmente, os ensinamentos eram transmitidos como verdades quase dogmáticas. Além de influenciar as obras pedagógicas no âmbito das escolas confessionais, o pensamento normativo e prescritivo também esteve presente nas iniciativas educacionais laicas desenvolvidas na Europa desde a Idade Média. No século XIX, o positivismo francês acentuou o caráter normativo, influenciando decisivamente os destinos da educação e das ciências sociais em todo o mundo ocidental.

O Brasil não é exceção à regra. Efetivamente, desde o Descobrimento até a Primeira República, as publicações sobre políticas educacionais e práticas de organização e administração do ensino eram memórias, relatórios e descrições assistemáticas, de caráter subjetivo, normativo, prescritivo e legalista. Foi somente no contexto da efervescência política e cultural das décadas de 1920 e 1930 que nasceu a administração educacional como campo profissional de estudo. Foi nessa época que a disciplina Administração Escolar e Educação Comparada passou a integrar os currículos dos cursos de licenciatura das Faculdades de Filosofia, Ciências e Letras, destinados à formação de educadores e professores para a educação básica. Foi nesse contexto que apareceram as primeiras obras especializadas no campo das políticas públicas e da administração do ensino, com destaque às publicaçôes de Anísio Teixeira (1935), Querino Ribeiro (1938), Carneiro Leão (1939) e Lourenço Filho (1941). Todos adotaram a denominação de administração escolar em seus trabalhos. No entanto, Lourenço Filho e Anísio Teixeira também falam em administração do ensino e administração educacional, no contexto da administração pública, já sinalizando uma tendência mais sociológica no estudo das políticas educacionais e da administração do ensino. 
Um passo decisivo para a consolidação da administração educacional como campo profissional de estudo no Brasil foi a fundação da Associação Nacional de Professores de Administração Escolar (Anpae), em 1961, na Faculdade de Educação da Universidade de São Paulo, sob a liderança de Querino Ribeiro (USP), Anísio Teixeira (UDF), A. Pithon Pinto (UFBA), P. de Almeida Campos (UFF) e outros reconhecidos professores catedráticos de Administração Escolar e Educação Comparada. A Anpae adotou, no seu nascimento, os princípios e práticas da escola clássica de administração e, sob a liderança dos mestres fundadores, a produção do conhecimento no campo da administração do ensino se enriqueceu crescentemente com as contribuições das ciências sociais. Atento a essa evolução, os organizadores do IX Simpósio Brasileiro de Administração Educacional, realizado em julho de 1978 na Universidade Federal do Paraná, lideraram um movimento nacional para estudar a política e a administração da educação no contexto das ciências sociais. O Simpósio, que foi um marco na história do pensamento administrativo da educação brasileira, avançou na concepção da especificidade da administração no campo do ensino e cunhou a expressão administração da educação, preparando, assim, o caminho para a mudança do próprio nome da Anpae para Associação Nacional de Profissionais de Administração da Educação, fato que ocorreu em 1982 no Rio de Janeiro. O enfoque de ciência social aplicada também foi o tema central do I Congresso Interamericano de Administração da Educação, realizado em 1979, em Brasília, sob os auspícios de associações profissionais de educação e organizações internacionais de cooperação educacional, com o objetivo de estudar a relação entre política e administração da educação, enfoque que, em 1995, foi incorporado ao próprio nome da Anpae - Associação Nacional de Política e Administração da Educação.

Essa leitura histórica revela que, ao longo da nossa vida republicana, o termo administração dominou o pensar e o fazer a educação. Atualmente, no entanto, uma série de termos disputam seu espaço semântico, destacando-se os de gestão, gerência e governação. Há duas décadas, o termo gestão era praticamente inexistente na teoria e na prática da educação brasileira. Os primeiros que se aventuraram a utilizá-lo eram encarados com ar de desconfiança, até mesmo de desaprovação. Desconfiança e desaprovação provavelmente porque os primeiros a adotar o termo gestão tenham sido os administradores de empresa, que o traduziram do management anglo-americano, da gestion par les systêmes dos franceses, enfim, da gerência racionalizadora e instrumental dos homens de negócios. Desconfiança e desaprovação, talvez, porque o termo gestão, assim como o de gerência, nos tenha sido trazido de além-mar, pelos representantes do pensamento liberal que atuavam nos bancos internacionais de desenvolvimento e nos organismos multilaterais de cooperação técnica. Na realidade, para muitos analistas, a adoção dos termos gestão e gerência representa mais uma transposição, tão comum na história do pensamento administrativo brasileiro, de categorias analíticas e praxiológicas da administração empresarial para a administração do Estado e da educação.

$\mathrm{O}$ certo é que o termo gestão vem se impondo crescentemente no pensamento administrativo do setor público e da educação brasileira. É consagrado na Constituição de 1988, na Lei de Diretrizes e Bases da Educação Nacional de 1996 e em numerosos instrumentos legais dos sistemas de ensino do País. Integra o vocabulário politizado dos movimentos sindicais e outras entidades da sociedade civil organizada. Enfim, representa 
hoje o novo discurso político e administrativo no governo da coisa pública e da educação, tanto estatal como privada, confessional ou não. É assim no Brasil e em outros países da América Latina, como tem sido antes na Europa e na América do Norte.

Cury (2002, p. 164), atendendo a uma demanda acadêmica sentida nessa matéria, explora a origem etimológica do termo gestão (de verbo latino gerere, gerar, exercer, executar), chamando a atenção para a postura dialógica subjacente ao conceito de gestão como forma de governo da educação em seus distintos níveis e modalidades de ensino. Lima (2002, p. 17-19) faz um exercício semântico semelhante com relação ao termo governação (do latim gubernatione, condução, direção, ação ou efeito de governar), destacando a idéia de processo, exercício e ação de governar, ao invés do enfoque funcionalista próprio do pensamento administrativo tradicionalmente adotado na educação ocidental. Ambos os autores completam suas explorações focalizando intervençōes democraticamente referenciadas, sinalizando, assim, uma tendência que hoje encontra apoio generalizado entre legisladores, pensadores e atores da política e da administração da educação. Nasce, assim, o conceito de gestão democrática da educação, consagrado na Constituição Federal de 1988 e na Lei de Diretrizes e Bases da Educação Nacional, de 1996.

No campo do ensino superior, destaca-se o debate conduzido por Sguissardi sobre o desenvolvimento da chamada universidade neoprofissional, heterônoma e competitiva, que se configura a partir do ajuste neoliberal na economia e da reforma do Estado nos anos 1990, trazendo novos critérios e indicadores para definir distintos modelos de gestão universitária (SGUISSARDI, 2003, p. 8). Para efeitos analíticos, Sguissardi classifica as instituiçôes brasileiras de ensino superior em neonapoleônicas e neo-humboldianas. Segundo a sua definição, as primeiras oferecem limitada estrutura para a pesquisa e a pós-graduação stricto sensu; nelas predominam professores contratados precariamente, em regime de tempo parcial ou de horista, e com limitada qualificação pós-graduada; nelas as atividades são desenvolvidas em institutos ou unidades isoladas e existe dedicação quase exclusiva ao ensino em sala de aula. Em suma, o seu caráter é essencialmente profissionalizante e com limitada produção intelectual. Já nas instituições neo-humboldianas, existem estruturas consolidadas de produção científica e de pós-graduação stricto sensu; presença majoritária de docentes em regime de tempo integral e com qualificação em nível de pós-graduação; e integração das unidades acadêmicas em torno de programas e projetos comuns, preconizando uma estreita associação entre ensino, extensão e pesquisa científica. Em resumo, as instituições neo-humboldianas estão voltadas para a produção do saber e a formação de pesquisadores e pessoal especializado em distintos campos do conhecimento científico e tecnológico.

A literatura internacional apresenta inúmeros desenvolvimentos paralelos de gestão universitária em distintas partes do mundo, como, por exemplo, os protagonizados por Buchbinder (1993), Barrow (1996) e Bok (2003) no contexto da globalização. Bok, ex-Reitor da Universidade de Harvard, é particularmente contundente na sua análise crítica da crescente comercialização da universidade norte-americana, fazendo um chamamento para a preservação da missão intelectual e da cultura acadêmica da instituição universitária. À semelhança do trabalho de Sguissardi, esses e outros pensadores adotam uma classificação de gestão universitária voltada para as forças do mercado, em oposição a uma gestão universitária preocupada com a transmissão e produção do 
conhecimento social. Essa classificação serve de gancho para o exame de duas tendências atuais em matéria de políticas públicas e gestão da educação no Brasil, em seus distintos níveis e modalidades de ensino: (1) gestão produtiva, voltada para o mercado, com um viés econômico e comercial, e (2) gestão democrática, voltada para a cidadania, com uma orientação política e cultural.

Em resumo, independentemente da origem etimológica e de distintas aproximaçôes conceituais e praxiológicas, a gestão da educação está hoje instalada no Brasil como um conceito compreensivo que diz respeito ao pensar e ao fazer a educação em sua totalidade, visando o cumprimento de sua missão política e cultural e a consecução de seus objetivos pedagógicos. Nesse sentido, a gestão da educação abarca, desde a formulação de políticas e planos institucionais e a concepção de projetos pedagógicos para os sistemas educacionais e instituições escolares, até a execução, supervisão e avaliação institucional das atividades de ensino, pesquisa e extensão, e a administração dos recursos financeiros, materiais e tecnológicos.

A definição de gestão da educação aproxima-se, assim, dos conceitos de governo, governação ou governança, termos hoje extensamente utilizados na educação. No âmbito dessa definição compreensiva, desenvolvem-se as chamadas funções pedagógicas específicas nas instituiçôes de ensino, previstas na Lei de Diretrizes e Bases da Educação Nacional e em outros estatutos legais, como planejamento e administração escolar, inspeção e supervisão escolar, coordenação pedagógica e orientação educacional. O significado das habilitações pedagógicas no cotidiano da escola está em função da relevância política e cultural da gestão, que abarca a totalidade das relações que ocorrem no interior das instituições de ensino e entre estas e a sociedade. O seu caráter político e cultural introduz a discussão da formação e eleição dos profissionais responsáveis pela gestão ou governo da educação, assim como pela formação dos especialistas para as funções específicas de administração escolar, planejamento e avaliação, inspeção e supervisão, coordenação pedagógica e orientação educacional. Como a gestão da educação constitui uma função pública, a formação e eleição de seus atores sugere participação pública, vale dizer, sugere participação democrática, mediante um efetivo funcionamento, com poder de decisão, de colegiados e conselhos escolares e comunitários. Enuncia-se, assim, uma das grandes tendências na atual produção acadêmica no campo das políticas e da administração da educação brasileira, como se verá em seguida.

\section{DUAS VERTENTES ANALÍTICAS E PRAXIOLÓGICAS}

À luz desses antecedentes, é possível identificar duas vertentes atuais nos esforços de produção do conhecimento no campo da política e do governo da educação. Trata-se do enfoque produtivo, voltado para o mercado, e do enfoque democrático, voltado para a cidadania. Ambos têm raízes históricas nacionais e internacionais. O enfoque produtivo, de natureza comercial, é próprio das instituições neoprofissionalizantes e competitivas, voltadas para as forças do mercado, que, no atual contexto da globalização da economia e da atividade humana, são fortemente influenciadas pelo pensamento neoliberal dos centros de poder econômico nacional e internacional. $\mathrm{O}$ enfoque democrático, de natureza 
participativa, é próprio das instituiçōes científicas, que se preocupam primordialmente com a produção e disseminação do saber científico e tecnológico e com a formação política e cutural da cidadania.

\section{GESTÃO PRODUTIVA E POLÍTICA MERCADOLÓGICA}

O pano de fundo dessa tendência política e administrativa é o fenômeno da globalização da economia e da atividade humana, com suas conseqüências em termos de agudização da pobreza, da exclusão, da iniqüidade e do desemprego, que se manifestam de maneira persistente em todo o mundo, inclusive nos países desenvolvidos, mas com prejuízos particularmente graves para os países e as comunidades mais pobres.

À luz da globalização da economia e da atividade humana, as duas últimas décadas testemunharam um renovado interesse pelo estudo da política e da administração no âmbito internacional, com um enfoque centrado no conceito de governabilidade, definida em termos da capacidade de mediação dos centros de poder com a sociedade civil e as instituições que modelam a vida moderna. Os estudos de administração à luz do conceito de governabilidade ocupam lugar central nos programas das instituições de pesquisa e ensino dos países desenvolvidos. Nos Estados Unidos, por exemplo, um livro texto amplamente utilizado nos programas de pós-graduação em administração pública e ciências sociais é $A$ revolução global na gestão pública (KETTL, 2000). O livro, publicado pela influente Brookings Institution de Washington, DC, faz uma exposição propositiva dos principais modelos de reforma político-administrativa adotados nos países desenvolvidos, especialmente nos Estados Unidos e nas nações da Comunidade Britânica, e por eles exportados para o resto do mundo. Como resultado, multiplicam-se os esforços nacionais e internacionais em matéria de reformas institucionais e administrativas, tanto nas empresas como nas instituições governamentais.

O livro faz a apologia da eficiência econômica, da produtividade a qualquer custo e da privatização da gestão pública. Uma consequiência de sua aplicação é a atrofia do papel do Estado em temas fundamentais, como a segurança pública, a previdência social, a saúde pública e a educação, especialmente a educação superior, que hoje se transforma em objeto de negociação comercial no âmbito da Organização Mundial do Comércio (OMC). Simultaneamente, por causa da queda do poder aquisitivo de grandes contingentes da população, acentua-se a demanda social por políticas públicas que ensejem mais e melhores serviços sociais. Para enfrentar esse paradoxo, numerosos governos vêm ensaiando novas concepções políticas e soluções organizacionais e administrativas em diferentes setores da atividade humana, baseadas nos conceitos de eficiência e produtividade, visando melhorar o desempenho e reduzir custos.

O movimento internacional de atrofia do papel do Estado na formulação e execução de políticas públicas é, na realidade, um produto da pressão neocapitalista sem precedentes para privatizar muitas das atividades que, por sua natureza social e de utilidade pública, são responsabilidade precípua do Estado, como a segurança pública, a saúde pública, a previdência social e a educação pública. Um dos instrumentos de privatização da gestão pública tem sido a terceirização dos serviços do Estado. Limitada, na sua origem, 
à simples compra de serviços, a terceirização ramificou-se e gerou novas modalidades. Da prestação de serviços, passou à compra e venda de produtos, ou seja, à transferência de atividades e tecnologia, com aplicação a qualquer fase do ciclo produtivo, inclusive às atividades-fim.

Um recente desenvolvimento nos Estados Unidos, por exemplo, é a terceirização da própria administração escolar, segundo a qual, empresas especializadas são contratadas para gerir os negócios da escola. Nessa modalidade de administração escolar, o lucro determina o processo de decisões no interior da escola e o ensino corre o risco de virar comércio. Conseqüentemente, o desenvolvimento humano e a educação para a cidadania e a ética profissional passam a ocupar lugar subalterno. A terceirização chegou a tal proporção, que hoje seus protagonistas propõem dar um passo além (SILVEIRA et al., 2002), um passo para a quarteirização, definida como a gestão profissional da terceirização, campo ainda carente de suporte bibliográfico, mas já em plena vigência e com o devido enquadramento legal. A utilização dessas ferramentas na administração pública e na educação, estatal ou privada, requer um estudo detalhado sobre sua aplicabilidade, a fim de não comprometer suas atividades-fim, sua missão político-pedagógica e seus objetivos sociais e culturais.

$\mathrm{O}$ atual enfoque econômico da administração pública e educacional tem paralelos, se bem que mais sofisticados, com a perspectiva econômica do desenvolvimentismo da década de 1960, que marcou profundamente as ciências sociais nas décadas subseqüentes. As políticas públicas de educação e administração educacional daquela época sustentavam-se nos poderosos movimentos internacionais da economia da educação, da planificação de recursos humanos, das teorias do capital humano e do investimento no ser humano. À luz da lógica econômica que caracterizou esses movimentos, surgiu o planejamento governamental e, dentro dele, o planejamento educacional, fortemente impulsionado pelas agências de assistência técnica e financeira dos países desenvolvidos, pelos organismos intergovernamentais de cooperação internacional e pelas organizações multilaterais de crédito. O início do século XXI é testemunha de uma reedição, com nova roupagem, da lógica econômica do desenvolvimentismo do pós-guerra e que, na atual sociedade globalizada, gira em torno da ocupação de espaços políticos e militares e da defesa de poderosos interesses econômicos e comerciais, hoje mais evidente do que nunca nas negociações internacionais no âmbito da Organização Internacional do Comércio (OMC), e, neste hemisfério, nas negociações para o estabelecimento da Área de Livre Comércio das Américas (ALCA).

A lógica mercadológica que hoje domina a política e a sociedade também invade os meios acadêmicos, influenciando a formulação de políticas públicas e a concepção de perspectivas de gestão do Estado e de administração da educação. As palavras-chave dessas propostas são: eficiência econômica, competitividade e lucratividade, descentralização e privatização, qualidade total, estândares internacionais e avaliação de desempenho. O seu objetivo declarado é atingir elevados padrōes de qualidade institucional e desenvolvimento humano, para garantir a competitividade na nova sociedade do conhecimento. Esses fatos estão associados ao ressurgimento, após a queda do Muro de Berlim, do poder do ideário liberal, com sua lógica competitiva, alicerçada na concentradora economia da globalização e aliada à utilização maciça da tecnologia da informação. 
Os fatos indicam que essa lógica vem condicionando significativamente a produção e utilização do conhecimento, que, na expressão de Frigoto (1995), perdeu muito de sua histórica dimensão crítica, para tornar-se um instrumento a serviço de fins pragmáticos e utilitários, desprovidos de validade ética e de relevância política e cultural.

\section{GESTÃO DEMOCRÁTICA E POLÍTICA CIDADÃ}

A tendência democrática no pensar as políticas educacionais e no exercer a gestão da educação não surgiu do nada, nem é uma herança da divisão de poder feita pelo Estado ou governo de turno ou, ainda, uma dádiva das mantenedoras de instituições privadas de ensino. Ao contrário, o exame dos recentes desenvolvimentos revela que a gestão democrática é uma conquista, uma construção histórica que se insere nos movimentos sociais de reconstrução de nossas instituiçôes democráticas desde a ruptura institucional de 1964, incluindo os movimentos políticos das Diretas Já e da Constituinte, que culminou com a adoção da nova Carta Constitucional em 1988. Compreende também os movimentos de resistência e renovação protagonizados pela Sociedade Brasileira para o Progresso da Ciência (SBPC), pela Conferência Nacional dos Bispos do Brasil (CNBB) e outras entidades da sociedade civil organizada em distintas áreas do conhecimento.

No campo da educação, o movimento de reconstrução democrática vem acompanhado da organização e consolidação de uma série de sociedades científicas e associações de educadores, como a Anped, a Anpae, a Andes, o Cedes, a Undime, a Anfope e o Consed. A construção democrática engloba ainda o movimento renovador das Conferências Brasileiras de Educação e está associada à crescente produção científica e ao rápido desenvolvimento da pós-graduação em nossas universidades, apoiadas pela Capes e pelo CNPq. Finalmente, o movimento da construção democrática manifestou-se na mobilização da sociedade civil em torno da nova Lei de Diretrizes e Bases da Educação Nacional de 1996, da defesa da escola pública e da luta pela profissionalização dos educadores e a valorização do magistério.

A tendência democrática na educação brasileira é evidente na legislação do ensino, nas práticas de gestão da educação em seus distintos níveis e modalidades de ensino e na produção acadêmica das universidades e instituições de pesquisa, socializada pelo parque editorial e pelas agremiações de educadores. $\mathrm{O}$ conceito de gestão democrática tem particular apelo nos meios universitários. Na Enciclopédia de Pedagogia Universitária (2003, p. 321-323), Morosini, Franco e Luce fazem uma aproximação do conceito de gestão democrática ao pensar e ao fazer a universidade, explorando seus aspectos humanos, políticos e culturais, num esforço de superação do caráter essencialmente técnico e burocrático da tradição brasileira de administração do Estado e da educação.

O princípio da gestão democrática está consagrado no artigo 206 da Constituição Federal, no artigo $3^{\circ}$ da Lei de Diretrizes e Bases da Educação Nacional e em numerosos estatutos legais dos sistemas estaduais de ensino. As leis de ensino asseguram a autonomia da escola pública, a participação dos educadores na elaboração do projeto pedagógico da escola e a participação da comunidade escolar e da comunidade local em conselhos escolares. Essas disposições dão aos educadores e à comunidade a base legal para exercer 
o controle democrático sobre os serviços educacionais prestados pelo Estado. Também confere à comunidade o direito de participar no fazer pedagógico como extensão do fazer educacional da família e da sociedade.

No entanto, são inúmeras as limitações e distorções da legislação em matéria de democratização da gestão da educação brasileira (PARO, 1998). Falhou o legislador ao restringir a gestão democrática ao ensino público, numa clara demonstração da influência da lógica do mercado no processo legisferante. Falhou o legislador em não definir claramente as atribuiçôes do governo federal em matéria de gestão democrática da educação. Falhou o legislador ao não prever, nas disposiçōes sobre a autonomia escolar, a transferência de efetivo poder de decisão às escolas. Não obstante essas e outras limitações da legislação, o conceito de gestão democrática está claramente consagrado na Carta Magna e na Lei de Diretrizes e Bases da Educação Nacional, dando aos educadores e à comunidade os elementos básicos para a conquista de novos espaços para o seu exercício no cotidiano da escola, tanto estatal como privada, confessional ou não.

É alentador verificar que a prática escolar e a produção acadêmica em matéria de gestão democrática vão além dos dispositivos da legislação educacional brasileira. É impossível relacionar aqui as numerosas contribuições individuais dos pensadores críticos que, nas últimas décadas, enriqueceram o debate político-pedagógico em torno da gestão democrática da educação. Por outro lado, mais importante do que examinar contribuiçôes individuais, é registrar os temas que vêm convocando a atenção coletiva de políticos e educadores. Nesse sentido, é imprescindível registrar a valiosa produção intelectual realizada em nossas universidades, especialmente nos programas de pós-graduação stricto sensu, e socializada pelas associações de educadores, em particular a Anped e a Anpae. É precisamente na produção intelectual de nossas universidades que a gestão democrática aparece como tendência dominante nos recentes estudos brasileiros de educação.

As tendências são evidentes na eleição dos temas de estudo nos meios acadêmicos e nas organizações da sociedade civil organizada. Nesse sentido, é preciso destacar a importância do recente estudo sobre a construção do conhecimento em políticas e gestão da educação brasileira, realizado pela Anpae, no período de 1996 a 1999. Em boa hora, o Instituto Nacional de Estudos e Pesquisas Educacionais (Inep) e a Fundação Ford financiaram a pesquisa, coordenada por Wittmann e Gracindo, sobre $O$ estado da arte em política e gestão da educação no Brasil (2001). O estudo, que envolveu uma extensa rede de pesquisadores e instituições universitárias do País, retrata importantes tendências que se manifestam nos meios intelectuais, especialmente nas universidades. Efetivamente, $64 \%$ das pesquisas revisadas no estudo são dissertações de mestrado e teses de doutorado. Mais de 30\% das pesquisas avaliadas se refere às políticas de educação e à formação e atuação dos profissionais da educação. E, finalmente, $25 \%$ das pesquisas se refere especificamente à gestão da escola e à administração universitária. Ou seja, políticas públicas, magistério e gestão da educação são hoje temas prioritários para os estudiosos da educação brasileira.

É importante destacar que a temática presente ao longo de todo o estudo da Anpae é o da democratização da educação e, nesse contexto, da democratização da gestão da educação, envolvendo questōes como municipalização, descentralização, autonomia e participação, tanto interna quanto externa, na condução dos destinos de nossas instituiçôes e sistemas de ensino. A inserção social da escola, o papel dos movimentos sociais 
na educação e a gestão municipal estão presentes ao longo de todo o trabalho. A promoção das práticas democráticas e a formação para a cidadania ocupam lugar central nas considerações específicas sobre a gestão escolar e a administração universitária. Em 45,5\% dos estudos que integram a obra da Anpae aparecem, como temáticas fundamentais, a centralidade da escola, a democratização de sua gestão e a autonomia pedagógica, envolvendo a organização do trabalho escolar e o papel dos atores da gestão escolar, como administradores, diretores de escola, coordenadores e assistentes de direção, supervisores, alunos e representantes da comunidade local.

\section{À GUISA DE CONCLUSÃO}

A produção do conhecimento em políticas e gestão da educação engloba um extenso campo de estudos e pesquisas. Este trabalho se limitou a examinar duas vertentes analíticas e praxiológicas: a gestão produtiva, voltada para o mercado, e a gestão democrática, voltada para a cidadania. A primeira se insere no contexto da lógica econômica e comercial própria do fenômeno internacional da globalização. A segunda se insere nos movimentos sociais que lutam pela qualidade de vida humana na escola e na sociedade, alicerçada na participação eqüitativa nos bens econômicos e culturais produzidos coletivamente.

As evidências empíricas sugerem que o conceito de gestão democrática está hoje instalado no pensamento administrativo do setor público e da educação brasileira. O conceito está efetivamente consagrado na Constituição Federal de 1988, na Lei de Diretrizes e Bases da Educação Nacional de 1996 e em numerosos instrumentos legais dos sistemas de ensino do País. Diante desse enquadramento legal, a gestão democrática da educação representa hoje o discurso político e administrativo no governo da educação brasileira, tanto estatal como privada, confessional ou não. No entanto, ainda enfrentamos o desafio de traduzir o discurso político e administrativo para efetivas práticas democráticas em numerosas instituições de ensino do País.

As duas últimas décadas são testemunhas do crescente engajamento político dos educadores na construção da democracia e da gestão democrática como caminhos efetivos para fazer frente às poderosas forças do mercado que inspiram a gestão produtiva da educação. Os fatos comprovam que a gestão democrática da educação não é uma concessão governamental, nem uma dádiva das mantenedoras de instituiçóes privadas de ensino. Ao contrário, é uma construção histórica da sociedade civil organizada, que enriquece a nossa memória educacional.

Trata-se, obviamente, de um desafio de enormes proporções, que implica em uma filosofia política e uma estratégia de ação pedagógica. No dizer de Gadotti, a gestão democrática não se esgota na atitude democrática, ela requer também métodos democráticos de efetivo exercício da democracia. Impóe-se, portanto, criar oportunidades de educação cidadã, de trabalho e aprendizado coletivo, visando desenvolver uma efetiva participação no pensar e no fazer a educação, e promover estratégias de ação humana coletiva na formulação e execução de políticas educacionais. De ser assim, teremos contribuído para o fortalecimento da democracia na escola e na sociedade e para o enriquecimento de nossa memória educacional e nossa herança civilizatória. 


\section{Referências}

BARROW, Clyde W. The strategy for selective excellence: redesigning higher education for global competition in a pre-industrial society. Higher Education: international journal of higher education and educational planning, v. 31, p. 447-469, 1996.

BOK, Derek. Universities in the marketplace: the commercialization of higher education. New Jersey: Princeton University Press, 2003.

BUCHBINDER, Howard. The market oriented university and the changing role of knowledge. Higher Education: international journal of higher education and educational planning, v. 26, p. 331-347, 1993.

CURY, Carlos Roberto Jamil. Gestão democrática da educação: exigências e desafios. Revista Brasileira de Política e Administração da Educação, São Bernardo do Campo, v. 18, n. 2, p. 163-174, jul./dez. 2002.

FAYOL, Henri. Administration industrielle et générale. Paris: Dunod, 1916.

FRIGOTTO, Gaudêncio. Educação e a crise do capitalismo real. Petrópolis: Vozes, 1995.

KETTL, Donald F. The global public management revolution: a report on the transformation of governance. Washington: Brookings Institution Press, 2000.

LEÃO, Antônio Carneiro. Introdução à administração escolar. São Paulo: Melhoramentos, 1939.

LIMA, Licínio. Organização escolar e democracia radical: Paulo Freire e a governação democrática da escola pública. Campinas: Cortez, p. 17-19, 2002.

LOURENÇO FILHO, Manoel Bergström. Organização e administração escolar. São Paulo: Melhoramentos, 1963 (Originalmente publicado em 1941).

MORISINI, Marília Costa et al. Enciclopédia de pedagogia universitária. Porto Alegre: FAPERGS/RIES, p. 321-325, 2003.

PARO, Vitor Henrique. O princípio da gestão democrática no contexto da LDB, Revista Brasileira de Política e Administração da Educação, Porto Alegre, v. 14, n. 2, p. 243-251, jul./dez. 1998.

RIBEIRO, José Querino. Fayolismo na administração das escolas públicas. São Paulo: Faculdade de Filosofia da Universidade de São Paulo, 1938.

SANDER, Benno. Administração da educação no Brasil: é hora da relevância. Educação Brasileira, Brasília, v. 4, n. 9, p. 8-27, 1982.

- Política e gestão da educação no Brasil: momentos e movimentos. Revista Brasileira de Política e Administração da Educação, Porto Alegre, v. 17, n. 2, p. 263-276, jul./dez. 2001.

SGUISSARDI, Valdemar. A universidade neoprofissional, heterônoma e competitiva. Anais da Reunião Nacional da ANPEd, 24. Rio de Janeiro: DP\&A, 2003.

SILVEIRA, Adriano Dutra da et al. Um passo além da terceirização. Porto Alegre: Badejo Editorial, 2002.

TAYLOR, Frederick W. Principles of scientific management. New York: Harper and Row Publishers, 1911.

TEIXEIRA, Anísio Spínola. Educação pública, sua organização e administração, 1935. Ver também TEIXEIRA, Anísio Spínola. A administração pública brasileira e a educação, Revista Brasileira de Estudos Pedagógicos, Rio de Janeiro, v. 25, n. 61, 1956.

WEBER, Max. The theory of social and economic organization. New York: The Free Press, 1947 (original publicado na Alemanha em 1921).

WITTMANN, Lauro Carlos; GRACINDO, Regina Vinhaes. O estado da arte em política e gestão da educação no Brasil de 1991-1997. Campinas: Autores Associados/Anpae, 2001. 


\section{B. Sander}

\section{The production of knowledge in educational policy and management}

\section{Abstract}

The study of the production of knowledge in educational policy and management is a major concern in academic and professional circles in Brazil. This paper is part of this scholarly effort. It dwells upon two major trends which today occupy a growing space in the study of educational policy and management: productive management, based on market policies, and democratic management, concerned with the development of citizenship. The first trend responds to the economic and business logic that characterizes today's global society. The second emerges from the social movements in their quest to promote the quality of human life within the school and in society, defined in terms of equitable participation in the economic and cultural benefits produced collectively.

Keywords: Public policies. Educational policy. Democratic management versus productive management in education. Participation. Citizenship.

\section{La production du savoir dans les politiques et gestion éducationnelles}

\section{Résumé}

L'étude de la production du savoir dans le domaine de la politique et de la gestion éducationnelle est devenue un sujet prioritaire dans les milieux académiques et professionnels au Brésil. Cette étude sinsère dans cet effort intellectuel. Son objectif est d'examiner les deux lignes qui occupent aujourd'hui un plus grand espace dans la littérature spécialisée : la gestion productive centrée sur le marché et la gestion démocratique en accord avec la citoyenneté. La première ligne sinsère dans le contexte de la logique économique et commerciale propre de la société actuelle globalisée. La seconde est une conquête des mouvements sociaux qui luttent pour la promotion de la qualité de la vie humaine dans l'école et la société, celle-ci étant définie em terme de participation équitative dans les biens économiques et culturels produits collectivement.

Mots clefs : Politiques publiques. Politiques éducationnelles. Gestion démocratique versus gestion productive en éducation. Participation. Citoyenneté.

\section{La producción del conocimiento en políticas y gestión de la educación}

\section{Resumen}

El estudio de la producción del conocimiento en políticas y gestión de la educación ha merecido atención prioritaria en los medios académicos y profesionales de Brasil. Este trabajo se inserta en ese esfuerzo intelectual. Su objectivo es examinar dos vertientes que hoy ocupan cresciente espacio en la literatura especializada: la gestión productiva, dirigida al mercado, y la gestión democrática, comprometida con la ciudadania. La primera vertiente está insertada en el contexto de la lógica económica y comercial propia de la actual sociedad globalizada. La segunda es una conquista de los movimientos sociales que luchan por la promoción de la cualidad de vida humana en la escuela y en la sociedad, definida en términos de participación equitativa de los bienes económicos y culturales producidos colectivamente.

Palabras-clave: Politicas públicas. Política educacional. Gestión democrática versus gestión productiva en educación. Participación. Ciudadania. 